The mathematical foundations of the subject were covered in a core of six lectures by D. G. Kendall and supported by a further four by F. Downton and R. R. P. Jackson, and the applications of the theory to 'machine interference' and to other practical problems were explained in nine further lectures by F. Benson and others. Two representatives of the Mathematisch Centrum, Amsterdam, also attended the course and contributed greatly to its success.

To one observer the course illustrated the growing importance of applied probability theory as a subject in its own right, and also demonstrated the encouraging fact that, when sufficient trouble is taken, the mathematical subtleties of the theory of stochastic processes can be expounded in a form acceptable to the industrial mathematician. It is generally felt that the course was a success, and a repetition is now being planned to take place in July of the present year.

\section{SCIENCE IN FRANCE}

$\Lambda \mathrm{N}$ article entitled "Science in France" by Dr. A. C. Copisarow, who is scientific attaché at the British Embassy in Paris, appeared in the winter issue of Britain and France, the quarterly journal of the Franco-British Society (Vol. 12, 1956; $1 s$. net). Research in France is organized at three levels. First, under the control of the Ministry of National Education are the universities, the Grandes Écoles and the forty laboratories throughout the country administered by the Centre Nationale de la Recherche Scientifique, which corresponds roughly to the British Department of Scientific and Industrial Research. The Association Nationale de la Recherche 'Technique, the main French technological research complex, has no counterpart in Britain. Secondly, there are some thirty industrial co-operative research organizations, financed by the industries they serve. Finally, there are a number of private establishments, ranging from the Pasteur Institute to the research departments of individual companies.

'The development of nuclear power in France began slowly after the Second World War, but in $1955 \mathrm{M}$. Gaston Palewski prepared a comprehensive plan and obtained for the Atomic Energy Commission the equivalent of $£ 100$ million for research and development during 1955-58, to be spent chiefly on industrial contracts. At present, about 1,800 technologists are employed in work on atomic energy in France, as compared with 1,000 for the rest of western Europe, $\mathbf{5 , 0 0 0}$ in Britain and $\mathbf{1 5 , 0 0 0}$ in the United States. The first nuclear reactor is in small-scale operation at Marcoule, near Avignon, a second is scheduled to begin later this year, and a third in 1958, when a total of $50,000 \mathrm{~kW}$. of electric power from nuclear sources will be added to the national grid system. The $200 \mathrm{lb}$. of plutonium produced annually by the three reactors at Marcoule will be used industrially ; it is not intended to manufacture bombs, but the design of nuclear marine and submarine engines is being investigated.

There is a severe shortage of scientific man-power in France, due chiefly to post-war disorganization of the educational system. Of 151,000 students enrolled in 1954 , only 29,000 were studying science or engineering: of these, only 3,900 reached the standard required for the diploma and a mere 650 continued as research students. The recent Landucci Com- mission on Scientific Man-power recommended that the number of scientific and engineering students should be doubled within the next decade and that more grants should be provided for postgraduate work. The Higher Council for Scientific Research and Technical Progress, under the chairmanship of Prof. Henri Longchambon, has also undertaken a detailed inquiry into the deployment of French technological resources. It has initiated a comprehensive stocktaking of the nation's scientific potential in men and materials, defining and financing a number of national research objectives; it is investigating the existing conditions of training scientists and the industrial exploitation of their discoveries; and it is examining the co-ordination of research and the communication of information between the various research organizations.

\section{FORECASTING TORNADOES AND SEVERE THUNDERSTORMS}

7 HE publication by the United States Weather Bureau of "Forecasting Guide No. l"*, the first of a series, stimulates thought on the degree of official guidance given to weather forecasters. Directors of meteorological services have never, so far as is known to the writer, considered it advisable to lay down fixed rules of forecasting procedure. They have recognized that it is impossible to legislate for all the complex details of the weather and that the forecaster must be given all the information likely to be helpful to him and then offered every encouragement to use his best judgment. 'I'his new 'forecasting guide' is unusual in that it seems to be the first time a major meteorological service has produced a publication with so definite an indication of offieial approval of a code of practice as is implied in the title 'guide'. It is, however, an aid to decision, not a set of rules. We find, in fact, the sentences: "In common with other types of weather forecasting the formulation of a tornado forecast does not entail a simple weighing of parameters or direct application of rules. Instead, the forecaster must arrive at some decision, or series of decisions, in each individual situation regarding the combined relative importance of the climatological, synoptic, thermodynamic and dynamic factors previously discussed".

Tornadoes cause great damage in central North America but are very infrequent at any one place. During June, between 3 p.m. and 9 p.m., in which tornadoes are most frequent in Kansas, the overall probability that one will appear in an area of 20,000 sq. miles on a day chosen at random is only $0 \cdot 04$. This is much lower than the climatological probability of other phenomena covered in weather forecasts. Tornado warnings enable some useful protective steps to be taken, such as sheltering underground and alerting first-aid workers, yet a warning naturally causes great anxiety which should only be aroused for very good reason. The guide includes a history of tornado forecasting which shows that, after some tentative efforts at forecasting in the nineteenth century, the United States Weather Bureau from 1905 until 1938 specifically prohibited mention of the word 'tornado' in the forecasts because

* United States Department of Commerce: Weather Bureau. Forecasting Guide No. 1: Forecasting Tornadoes and Severe Thunderstorms. Edited by Jay S. Winston. Pp. v+34. (Washington, D.C. : U.S. Department of Commerce, 1956.) 
of the alarm it caused. Forecasters were, however, instructed to predict 'severe local storms'. From 1938, however, the word 'tornado' has been permitted, and a strenuous effort has been made to specify more exactly the meteorological conditions favourable for the formation of tornadoes. The latest stage was the setting up by the United States Weather Bureau in 1952 of a research unit called the Severe Local Storms Centre, which formed at Washington and moved to Kansas City, in the heart of tornado country, in 1954.

The booklet under review is the first publication of the Centre. The climatology of tornadoes in time and space is described in some detail. Next are given the favourable air mass types in terms of the vertical distributions of temperature and water vapour. These are all naturally unstable in one way or another. The most important type of air mass is one with convective instability in which condensation begins at the bottom if the air mass is lifted. Once condensation has begun in the lower part, the upper part cools on lifting at the dry adiabatic rate compared with the smaller saturated adiabatic rate of the lower part so that the degree of instability quickly increases. Tornadoes are nearly always associated with thunderstorms and with the south-east sector of a depression. They seem to be associated with definite centres of low pressure and do not occur in sporadic 'air mass' or 'heat' thunderstorms. The instability has to be released by vertical ascent and the variations of wind speed with height favourable for convergence and vertical movement have been studied at the Centre. The forecast is formulated from consideration of the advection of heat and water vapour to produce a suitable vertical distribution and of the suitability of the wind structure for convergence. It is stated that in the first seven months of 1955,1 in 3 of all areas for which tornadoes were forecast, each area averaging 20,000 sq. miles, contained at least one tornado during the period of the forecast. For so exceptional a phenomenon this seems a very useful proportion.

No mention whatever is made in the booklet of how a tornado actually forms; everything is devoted to determining the likelihood of convective overturning. This is certainly necessary, but is it sufficient ? Lamb (Meteorological Office Geophysical Memoir 99, in the press) has suggested that surface features producing opposing winds are source points for tornadoes. The distribution of formation points of tornadoes might be worth examining for points of concentration.

\section{MINERAL NUTRITION AND AMINO-ACIDS IN TOMATO}

$T$

HE level and the quantitative composition of the free amino-acid fraction of tomato plants grown in full nutrient and in cultures deficient in zinc, copper, manganese, iron and molybdenum have been determined by J. V. Possingham (Austral. $J$. Biol. Sci., 9, 539 ; 1956).

The methods used in the investigation include the quantitative estimation of amino-acids by a technique involving paper chromatography, and the culture of tomato plants in highly purified nutrient solutions. All the deficiencies investigated except that of molybdenum brought about increases in the free amino-acid fraction. In every case there was a change in the quantitative composition of this fraction. Iron and zinc deficiencies were associated with large increases in the free levels of the two amides asparagine and glutamine, while with copper and manganese deficiencies many individual aminoacids increased in concentration, but not the two amides. The level of total free amino-acids and amides was low in molybdenum-deficient plants. The qualitative differences between deficient- and fullculture plants were not large, but included the accumulation of $\beta$-alanine with deficiency of zinc, copper or molybdenum, and of pipecolinic acid with deficiency of manganese or iron. Other differences were the absence of histidine with copper, manganese, iron and molybdenum deficiency, of phenylalanine with copper deficiency, and of lysine with copper, manganese and molybdenum deficiencies. Additionally many quantitative changes in amino-acid concentration were found. In the deficient plants there were changes in the concentration of most aminoacids relative to the levels in the controls. These changes were not uniform, and the relative amounts of the different amino-acids were altered with each deficiency.

The significance of these experimental results is discussed in relation to the known interactions between the mineral nutrition and the amino-acid composition of plants. Although a characteristic spectrum of free amino-acids is associated with each individual deficiency, the differences are not considered sufficiently large to make analysis for these compounds an additional method for the diagnosis of mineral deficiencies in this plant.

\section{'L FORMS' OF BACTERIA}

$\mathrm{T}$ HE members of the "Réunion sur les Formes $I_{\text {s }}$ et sur les formes évolutives des bactéries", held in Lausanne during May 17-18, 1956, have issued the following statement :

(1) Numerous cycles of different bacteria have been described under different names-L forms, filtrable invisible forms, evolution forms, etc. Often enough, all these bacterial forms have been describer under the name of ' $L$ cycle'. At the present state of our knowledge, it seems preferable to use different designations, in order to describe phenomena and appearances which are perhaps not the same.

(2) E. Klieneberger-Nobel has used in all her papers published in English the expression ' $L$ forms' in order to designate bacterial colonies of new appearance which occur in vitro spontaneously or by stimulation. It seems, however, that the English word 'form' has been interpreted incorrectly by a number of microbiologists using Latin languages. 'They have used this expression for the 'individual morphology of bacterial elements'. This incorrect interpretation manifests itself to-day when in the written or spoken language the following expressions are used : 'formes L naines', 'formes L globuleuses', etc. (Klieneberger-Nobel herself has occasionally made a similar mistake by using the expression ' $\mathrm{L}$ elements'.) E. Klieneberger-Nobel rejects completely the translation of the English 'form' into the French 'forme' and desires that it should be translated by the French word 'formation' and in German by 'Phase'. She is of opinion that one should designate as 'formation $L$ ' ( $L=$ Lister), ' $L$ form', ' $L$ Phase', the growth-form which can arise spontaneously or 